\title{
The Role of the Resident on the Psychiatric Inpatient Unit: A Systems Perspective
}

\author{
E. Michael Kahn, MD \\ Duke University
}

Follow this and additional works at: https://jdc.jefferson.edu/jeffjpsychiatry

Part of the Psychiatry Commons

Let us know how access to this document benefits you

\section{Recommended Citation}

Kahn, MD, E. Michael (1988) "The Role of the Resident on the Psychiatric Inpatient Unit: A Systems Perspective," Jefferson Journal of Psychiatry. Vol. 6 : Iss. 2 , Article 11.

DOI: https://doi.org/10.29046/JJP.006.2.009

Available at: https://jdc.jefferson.edu/jeffjpsychiatry/vol6/iss2/11

This Article is brought to you for free and open access by the Jefferson Digital Commons. The Jefferson Digital Commons is a service of Thomas Jefferson University's Center for Teaching and Learning (CTL). The Commons is a showcase for Jefferson books and journals, peer-reviewed scholarly publications, unique historical collections from the University archives, and teaching tools. The Jefferson Digital Commons allows researchers and interested readers anywhere in the world to learn about and keep up to date with Jefferson scholarship. This article has been accepted for inclusion in Jefferson Journal of Psychiatry by an authorized administrator of the Jefferson Digital Commons. For more information, please contact: JeffersonDigitalCommons@jefferson.edu. 


\title{
The Role of the Resident on the Psychiatric Inpatient Unit: A Systems Perspective
}

\author{
E. Michael Kahn, M.D.
}

\section{INTRODUCTION}

A resident in psychiatry is customarily assigned to inpatient duty for the first year of training. The resident's tasks in this setting are complex, and he ${ }^{1}$ is rarely prepared to perform all of them well $(1,2,3)$. The stress on the resident in this situation is great. Most often, these challenges and their mastery are discussed in terms of intrapsychic conflicts; the traditional remedy is the assignment of a supervisor. Little consideration has been given to the interpersonal and systems matrices in which these events occur, and the coping techniques and conceptual tools which the resident may use to meet these challenges. The resident may use knowledge of inpatient unit dynamics to develop strategies for accomplishing his tasks more effectively. Through these techniques, the resident can provide better patient care, further his professional growth, and reduce personal stress. Educators and administrators may assist the resident by developing a clear conception of the resident role, acknowledging the multiplicity of the tasks, and supporting the mastery of each task educationally and emotionally.

\section{THE PROBLEMS}

Too Many Jobs

The jobs of the beginning resident in the inpatient setting include: 1) Psychiatric diagnostician; 2) Psychotherapist; 3) Psychopharmacologist; 4) Team coordinator and treatment planner; 5) Primary care physician; 6) Learner in didactic and experiential modes; 7) Teacher and supervisor of medical students; and 8) Doctor “on call”. The resident's level of responsibility is high, his position in the decision-making hierarchy is intermediate, and his functional knowledge of the inpatient setting is low. The resident is expected to be "on

Eleanor $M$. White, $R N, P h D$, aided in the refinement of these ideas. The paper is dedicated to the memory of Frederick T. Melges, M.D. teacher and colleague.

${ }^{1}$ Throughout this paper, male third person pronouns should be taken to indicate individuals of either gender. 
top" of the situation. In fact, he is much closer to the bottom when it comes to authority and skill. His responsibilities often exceed his ascribed power, and he must find ways to achieve power (4) if he is to influence others.

\section{Conflicting Demands}

The resident's position is further complicated by conflicting or unclear conceptions of the resident's role. Training directors, unit managers, attending physicians, nursing staff, and the resident are often at odds in their expectations and their priorities. In some ways, "M.D." destines the resident to become a leader, yet he may find that others wish him to be an admiring spectator, a compliant errand boy, or a consummate therapist and troubleshooter. The resident's needs as a human being with life outside the hospital and his needs as a budding therapist may be ignored.

\section{Resident Reaction}

As the resident faces the conflict between these many expectations and demands, he will experience anxiety, identity confusion, and frustration $(1,2,3,5)$. It will seem impossible to find enough time for the essential tasks of patient care, professional learning, and personal growth. Depression and "burnout" are likely consequences. To survive, he must use his skills as a manager or coordinator to balance these demands, and enlist the aid of others in the patient care task. Skill as a psychotherapist or physician will not suffice, though these are common retreats. Native quickness and efficiency are a help, but are not sufficient in themselves. To succeed, the resident must develop a clear sense of the tasks at hand, a strategy for performing each of them, and a professional identification which will allow him to maintain a sense of accomplishment in the face of his many frustrations. A sound knowledge of organizational dynamics is most helpful.

\section{ORGANIZATIONAL DYNAMICS \& RESIDENT FUNCTION}

Effectiveness of the inpatient resident hinges largely upon his ability to establish a working alliance with the staff, his comprehension of the operating characteristics of the care system, and his ability to intervene and restore system to function when care tasks break down $(7,8,9,10)$.

\section{Alliance Phase}

Initial contacts between the resident and unit personnel are crucial in establishing a good working relationship. During this time, the resident should assess the system, determine how he might fit in, and begin to develop his relationship with the staff. He will identify the unit's approach to patient care, its 
decision-making structures, and the roles of the different groups within the organization (13). He should be sensitive to the emotional climate of the group, the position of the members vis a vis authority, and the sanctioned ways to get things done (14). Smooth function will be difficult because of the resident's relative ignorance of the system's norms, expectations, and dynamics.

The resident must move slowly and carefully during this phase. Successful development of an alliance with the staff depends on the resident's affirmation of system norms and conformance with the expectations of its members. The resident should align himself with the power holders of the system, and avoid threatening them or engaging in power struggles. The staff and the resident will test each other in a number of ways; knowledge, skills and personality characteristics will be surveyed as the resident responds to issues which arise. The "good resident" plays by the rules unless doing so will pose a threat to patients or staff. The resident who fails to do so will likely be labeled a "rebel" or "arrogant," and efforts will be made to isolate or eject him (15). If the resident wishes to make changes on the unit, then he should wait for the opportunities that present themselves once alliance is established.

\section{The Working Phase}

The resident and the unit staff will settle into a "working phase" once the anxieties and issues of the introductory phase have been, to some extent, resolved. The principal task of the resident in this phase is to use the resources at hand to fulfill his patient care responsibilities. These duties vary widely from hospital to hospital and unit to unit, and are determined by client needs, organizational resources, and organizational goals.

The resident is usually assigned to conduct supportive, brief, and/or pharmacologic therapies for individual patients. In addition, he is usually responsible for coordinating the efforts of the treatment staff on an hourto-hour basis. This activity takes place in a number of different arenas, including community meetings, team meetings, consultation with attending staff, and consultation with other ward personnel. The resident will be called when conflicts must be resolved expediently, and in medical and psychiatric crisis situations. He provides leadership on the unit in these several ways.

The most effective style of leadership will vary from unit to unit. In some organizations, the resident is expected to adopt an authoritarian role, dictating treatment plans to staff and providing little opportunity for their input. On some units, the resident is expected to act as a colleague, exercising authority by facilitating the emergence of consensus among staff members. On the other extreme, there are units which expect very little resident input. Unit staff will be uncomfortable if the resident does not approach them in the expected mode and metaphor. The staff will attempt to shape the resident's behavior, and, if their efforts fail, they may develop ways to exclude him from decision-making activities. The resident may collude by deferring decisions inappropriately, by 
refusing to take responsibility, by being unavailable to the staff, or by blaming the staff for "not respecting me as a doctor". Usually, the resident is able to identify the expectations of the staff and fill roles and assume responsibility appropriately. Patient will proceed smoothly until crises emerge.

\section{Vicious Circles}

The resident is "first call" when crises evolve on the inpatient unit. Often he is ill-prepared to handle these situations, and approaches them with a high level of anxiety. He is likely to overestimate the importance of his decisions, for his professional identity is not secure, and he is eager to "prove himself" to the staff on the ward. Because of these pressures, problems will seem more difficult to understand, and decisions harder to make.

The resident is called when other staff members decide that there is a "problem". The "problem" is an encapsulation of the staff's anxieties about a particular situation. As such, it may be based in either the identified patient or in the staff, and may be rational or irrational (11). It is quite tempting to assume that the problem is with the patient, and, as Main points out, it is "always the patient who is given the sedative" (18). Such misguided interventions may appear successful initially, for any action on the part of the resident (the transferentially endowed authority figure) is likely to reassure the staff and mollify the patient (9). If the problem is truly not with the patient, it will re-emerge. It is the resident's job, then, to decide where the problem is, and what intervention will be most helpful.

Organizational factors will play an important part in the ways in which problems are generated, diagnosed, and resolved. A great number of individuals are involved in the unit's function, and it is difficult for the many personalities to cohere into a single "ego" (16). The organization, therefore, is dominated by defenses such as idealization, reaction-formation, denial, splitting, projection, and acting out. Fear, anxiety, and sadness will be transmitted readily through both patient and staff groups. Interactions are intense, and good communication is hard to maintain. Psychiatric patients with demanding, manipulative character traits and primitive defenses will bring out the worst in the staff (17). The potential for organizational regression is high.

Once unpleasant affects have triggered an organizational regression, it is difficult to intervene. Primitive defenses leave the underlying conflicts unresolved, and lead to generation of "spin-off" issues. The result is a spiraling dysfunction which generalizes itself through the system. Breakdown occurs at different rates in the various subsystems; it is important to call upon the relatively intact subsystems to halt regression and restore equilibrium.

The resident should be alert to the emergence of such spirals. If he is caught up in the emotions of the moment, he will be functionally disabledunable to spot the problem or stop it. Instead, he should move to an analytic 
position, collecting and interpreting data about the process until he is able to make things make sense.

\section{Signs of Regression}

As the resident collects and analyzes the data, he should be alert to the signs and symptoms of organizational regression. These include:

1. Scapegoating-particular patients or staff members are identified as "bad" or "irresponsible" out of proportion to anything they have said or done (19);

2. Splitting - staff members argue over what should be done while the patient sits back, occasionally goading the staff on;

3. Transactional games-patients and staff may become involved in "Karpman's Drama Triangle," with the assignment of "victim," "persecutor," and "rescuer" roles (20);

4. Boundary crossing — staff members are going out of their way to do something they would not usually do, assuming excessive or inappropriate responsibility (13);

5. Violation of routine procedures - "special" patients are exempted from the usual ward rules, or unusually rigorous sets of standards are applied to problem patients $(18,21)$;

6. Deferral of decisions and abdication of responsibility - staff members postpone their usual decision-making tasks by rationalizing that the data are incomplete, that the decision doesn't matter, or that it isn't theirs to make (19);

7. Breakdown of the chain of command-staff members may "go to the top" rather than solving problems locally, or may "pull rank" when, in fact, decision by consensus is warranted;

8. Paradoxical positions - the demands of patient care seem to be at odds with standard procedures; the standard of care is vague; goals fly in the face of common sense (19);

9. Denial of limitations - staff members may assume that inability to care for a particular patient is a reflection of their personal inadequacy, and may "try hard" to persuade or coerce the patient into health. Alternatively, the staff may minimize the patient's difficulties insisting that the patient "talk it out," rather than imposing more restrictive, realistic solutions. The staff may not ask for help when they need it;

10. Excessive processing - talking, rather than acting, becomes the norm for intervention. The staff focuses on its issues rather than on the patients (22);

11. Retreat to a "Basic Assumption" stance-members may align themselves with one of Bion's sentience groups, i.e., Dependency, Fight/ 
Flight, or Pairing, and will relate to each other and to authority figures in this paradigm (23).

\section{Working Through}

Intervention often hinges on bringing the conflicts and resistances which are active into consciousness $(12,15)$. First, the resident should set limits on counterproductive behavior, and focus the staff's attention on constructive resolution of the situation. Blocking the emotional reaction aids problem solving. Second, the resident will work to increase awareness of the emotional factors underlying the regression, using clarification, confrontation, and interpretation. These acts will increase the level of anxiety and stimulate efforts to resolve conflict and repair anxiety management mechanisms. After unpleasant affects are expressed and tension is reduced, higher-level defenses may be brought into play. Resolution is accomplished as new problem-solving strategies are forged, sublimatory channels widened, and appropriate gratifiers found. The resident may activate and guide this process, stimulating awareness, offering information and support, enlisting high level defenses, and checking intolerable anxiety.

\section{Focus of Intervention}

Caplan describes two broad classes of interventions, the client-oriented and the system-oriented (9). He suggests that any particular intervention will be focused on one area or the other, but will impact upon both. The presenting problem will dictate the initial focus in the case; however, a shift in focus may be indicated as the assessment proceeds. The nature of these interventions is determined by the particular "lack" which the consultant finds. Lack of knowledge may be countered with education, lack of confidence with support, and lack of skill with supervision. Lack of objectivity is the most difficult of these to deal with because emotionally charged, unconscious issues are involved. Direct intervention, through clarification, confrontation, and analysis, is often successful. In particularly difficult situations, indirect interventions through the staff-resident relationship are necessary. For example, the resident might allow the staff of a unit to develop a dependent relationship to him. Then, through gradual clarification and interpretation, he could facilitate increasing independence, with mastery of fears of inadequacy. In general, the inpatient resident will receive client-focused requests, and will usually find it necessary to intervene through patient-centered action and metaphor.

\section{Follow-up}

Especially tough problems may exceed the authority, the analytic skills, or the interpretive capabilities of the resident. In these cases, it is essential for him 
to involve the "higher-ups" in analysis and intervention. The resident might avert conflict with an attending physician over a questionable admission by referring the matter to the chief resident or unit administrator. Questions about involuntary detention of a patient might be referred to hospital counsel, and matters concerning restriction of visitors to the hospital administrator. The resident should remember that he is the "expert" on psychiatry, on what is good for the patient, not what is good (or legal) for hospital or community. At times, it may be necessary to impose restrictive solutions while members of the policysetting body of the unit derive a policy which is the synthesis of therapeutic, ethical, administrative, and legal considerations. It is helpful to remember that there are few decisions in psychiatry which must be made in a matter of minutes.

\section{TASKS OF THE TRAINERS}

The hospital's managers and educators can take several steps to help the residents in their dilemma. It can establish the resident in a sound position as a care-provider by establishing clear norms and values, assigning responsibilities proportional to skill, and delegating appropriate degrees of authority. Through modeling, supervision, and didactic education, it will establish an information base and aid the development of professional identifications which will allow the resident to function as psychotherapist. Finally, the program may educate the resident as to the nature of these processes, so that he has the cognitive tools to function well, and can develop a strategy for avoiding "burn-out" $(7,8)$.

Role

Expectations regarding the resident's function will be embodied in the institution's written and unwritten policies, and its administrative and teaching structures. These expectations will be conveyed to the resident explicitly and implicitly. The educators and administrators in the institution will act consistently, in accordance with these norms. Boundaries between the different tasks will be kept clear, and explicit priority setting will aid allocation of resources and direction of effort at each turn. Appropriate balance between learning and service tasks will be struck, leaving sufficient time for life outside the hospital.

Development of a clear conception of the resident's role includes the elaboration of expectations which are consistent with the resident's level of skill. The level of authority given the resident will be commensurate with his responsibilities. He will be supported in his administrative position by his supervisors, chief residents, and service chiefs.

\section{Supervision}

Conflicts between the demands and expectations of the resident and those for whom and with whom he must work are inevitable. These conflicts will 
reduce the resident's effectiveness, and steps should be taken to prevent such impasses from developing. The faculty will assist the resident in compromise formation and working through, within limits appropriate to the training setting (25). They will help the resident establish reasonable expectations and goals, and find ways to meet personal and professional needs. Unrealistic expectations and negativism will be confronted squarely. The faculty will encourage peer support and catharsis.

\section{Curriculum}

The residents and faculty are likely to see training as a psychotherapist and pharmacotherapist as the core of the educational program, but other areas of knowledge must not be neglected. The program will include instruction in administration, organizational dynamics, and decision-making (6). Material regarding professional development and the burn-out syndrome will also be included $(7,8)$. This curriculum will help the resident to use his cognitive resources to understand and deal effectively with the problems he faces, and serve as the substrate for continued training in administrative psychiatry.

\section{SUMMARY}

The resident on the inpatient unit has many jobs, and often faces conflicting demands. He is in a poor position, strategically, to resolve this dilemma. The resident can simplify this task, increase his effectiveness, and decrease his stress by applying systems-oriented analysis and intervention. He will thus develop and maintain good working relationships with unit staff. He will watch for the vicious circles and regressive dynamics which make problem solving difficult. When problems do occur, he will be ready to intervene, restoring staff effectiveness. Finally, the resident will be able to take steps to change policy and procedure to avert problems in the future.

The hospital and the training program can work in concert with the resident to accomplish the goals of caring, learning and growing. They will delineate roles and expectations clearly, and will remain available to support the resident and assist problem solving. They will include material regarding organizational dynamics and administration in the curriculum.

\section{REFERENCES}

1. Tischler GL: The transition into residency. Am J Psych 128:93-97, 1972

2. Shershow JC and Savodnik I: Regression in the service of residency education. Arch Gen Psychiatry 33:1266-1270, 1972

3. Brent DA: The residency as a developmental process. J Med Educ 76:417-422, 1981

4. Wax J: Power theory and institutional change. Soc Service Rev 47:274-288, 1971 
5. Fleckles CH: The Making of a Psychiatrist: The resident's view of the process of his professional development. Am J Psych 128:101-107, 1972

6. Borus JF: Teaching residents the administrative aspects of psychiatric practice. Am J Psych 140:444-448, 1972

7. Gardner ER and Hall RC: The professional stress syndrome. Psychosomatics 22:672-680, 1981

8. Small GW: House officer stress syndrome. Psychosomatics 22:860-869, 1981

9. Caplan G: The Theory and Practice of Mental Health Consultation. New York, Basic Books, 81-190, 1970

10. Rogers K: Notes on organizational consulting to mental hospitals. Bull Menninger Clin 37:211-231, 1973

11. Miller WB: Psychiatric Consultation in the General Hospital. Rosenbaum, CP and Beebe, III, JE, in Psychiatric Treatment: Crisis/Clinic/Consultation. New York, McGraw-Hill, 496-704, 1975

12. Mohl PC: A systems approach to liaison psychiatry. Psychosomatics 21:457-461, 1980

13. Kernberg OF: A systems approach to priority setting of interventions in groups. Int J Group Psychother 27:251-275, 1975

14. Stein LI: The doctor-nurse game. Arch Gen Psych 16:699-703, 1967

15. Chaska NL: The "cooling out" process in a complex organization. J Nurs Administration 22-28, 1977

16. Kernberg OF: Leadership and organizational functioning: Organizational regression. Int J Group Psychother 27:3-27, 1977

17. Groves JE: Taking care of the hateful patient. N Eng J Med 298:883-887, 1978

18. Main TF: The ailment. Br J Med Psychol 30:129-147, 1957

19. Sacks MH, Carpenter Jr. WT: The pseudotherapeutic community: An examination of antitherapeutic forces on psychiatric units. Hosp and Comm Psychiatry 27:315318,1974

20. Levin P and Berne E: Games nurses play. Am J Nurs 72:483-487, 1972

21. Cottrane F, Puch CD: Danger signals in staff-patient relationship in the therapeutic milieu. J Psychiatric Nurs and Ment Health Services 34-36, 1978

22. Abrams RC and Sweeney JA: A critique of the process-oriented approach to ward staff meetings. Am J Psych 139:769-773, 1982

23. Rioch MJ: The work of Wilfred Bion on groups psychiatry 33:55-66, 1970

24. Whitney FW: How to work with a crock. Am J Nurs 87-91, 1981

25. Spiegel D, Grunebaum H: Training versus treating the psychiatric resident. Am J Psychother 31:618-623, 1977 